\title{
Examination of U.S. Finance-Related Industry Under COVID-19 Based on Fama-French model
}

\author{
Yuhan Cai ${ }^{1, \dagger}$, Yue Shen ${ }^{2, \dagger}$, Ting Wang ${ }^{3, \dagger}$, Tianning Xie ${ }^{4, *}, \dagger$ \\ ${ }^{1}$ Business school, University of Nottingham, Nottingham NG8 1BB, United Kingdom \\ ${ }^{2}$ Department of Mathematical Science, University of Liverpool, Liverpool L69 3BX, United Kingdom \\ ${ }^{3}$ School of Business Administration/School of Marxism, China University of Petroleum, Beijing, Karamay 834000, \\ China \\ ${ }^{4}$ Department of Statistics, London School of Economics and Political Science, London WC2A 2AE, United Kingdom \\ ${ }^{*}$ Corresponding author. Email: t.xie10@lse.ac.uk \\ These authors contributed equally.
}

\begin{abstract}
COVID-19 has had a tremendous influence on economic activity throughout the world. As the largest economy globally, the United States' finance-related industry changes have an essential impact on the world economy. The purpose of this paper is to evaluate the relative changes of each factor in the Fama-French five-factor model in the U.S. finance-related industry before (May 2019 to February 2020) and after (March 2020 to December 2020) the pandemic and test the applicability of this model. The Fama-French five-factor model, developed from the Fama-French three-factor model, considers the effects of systematic risk, book-to-market ratio, market capitalization factor, earnings factor, and investment factor on fund performance. It also provides a more comprehensive assessment of fund performance and a more effective measure of a fund's ability to achieve excess returns through active investment management. The results indicate that four sectors of Banking, Trading, Insurance, and Real Estate in the finance-related industry are sensitive and volatile to the COVID-19 crisis. Fama-French five factors of these sectors have reacted responsively to the outbreak. Especially for the Insurance and Real Estate, Robust minus Weak (RMW), High minus Low (HML), and Conservative minus Aggressive (CMA) have significant changes. In this paper, the performances of these four industries under the pandemic were discussed, and the reasons for the different reactions were analyzed. It is concluded that the COVID-19 outbreak has a particular impact on all finance-related industries, but the forms and degrees of effects are different in each sector.
\end{abstract}

Keywords: Fama-French five-factor model, Finance-related industry, COVID-19, U.S. stock market.

\section{INTRODUCTION}

\subsection{Background}

COVID-19 has a considerable impact on financial and economic activities worldwide due to its highly contagious nature, making it the largest black swan incident till now. In the context of economic globalization, the economies of all countries are interdependent and closely linked. The negative impact of COVID-19 has directly affected the financial industry of every country. The growth rate of the global economy has slowed down, and many countries have even registered negative growth. World stock indexes have fallen sharply. As the world's largest economy, the finance-related industry of the United States is very representative all around the globe. The most significant impact of this Coronavirus pandemic on financial markets has been in capital markets, where the United States stocks have been disrupted four times in two weeks. Under the influence of the pandemic and market conditions, the United States adopted a quantitative easing policy, increased QE many times. As a barometer of the state of economic operation, the financial market can optimize the allocation of resources and promote the transformations of savings and investments. Due to the high sensitivity of the financial market, selecting the finance-related industry as the research object can clearly show the impact of the pandemic on the economy.

An important tool of capital asset pricing, CAPM is widely used in asset valuation, capital cost budget, 
resource allocation, etc., and is necessary to support the modern financial market theory. The application of the CAPM model will measure the rationality of listed securities prices by predicting the expected rate of return and quantitative relationship to determine the prices of securities ready to appear on the market and estimate the impact of economic changes on their prices. Moreover, CAPM can help risk-averse investors find the optimal asset portfolio from many investment risks under the influence of COVID-19.

\subsection{Related Research}

The Fama-French five-factor model, which can effectively carry out asset pricing and performance evaluation, is an upgrade of the three-factor model and has been widely used. Horváth and Wang evaluated how Fama-French models performed on U.S. stock markets and what factors affect the variation of the financial markets. The models used in the research are GMM models and the Five-factor Fama-French model. More specifically, based on 12 months of data, the main factors focused on are $\mathrm{R}^{2}$, which is used to determine the ability of the Fama-French five-factor model to interpret the excess returns of stocks, and the beta coefficients, which gives the likelihood of infrequent events to occur in the future. In conclusion, the high value of $\mathrm{R}^{2}$ represents high statistical significance related to the stock market. Due to the pandemic, $\mathrm{R}^{2}$ experienced a continuous decrease. However, the beta coefficients are not essential for the GMM model [1].

COVID-19 has had a devastating impact on the global economy. The link between the number of confirmed cases and deaths from Coronavirus and stock market indices in various countries has also been a research point. Chikri et al. studied the relationship between the spread of the Coronavirus and the behavior of the financial market, including the United States, Italy, Spain, France, China, and Morocco. Data and descriptive statistics were used to support the three hypotheses: positive shocks lead to lower prices; negative shocks have a greater impact than positive shocks; during the reversals, the prices of the indices show a short-term overshoot. This study focuses on how to examine the possible asymmetric maturities in the short and long term through the relationship between price indices and COVID-19 in the existing literature, including the use of nonlinear co-integration methods and the confirmations of three hypotheses [2]. Hassan and Gavilanes conducted quantitative simulations of stock markets in the countries and worldwide commodity markets that suffered the first effects of Coronavirus. Compared to the above research, France and Morocco have been changed to Japan and South Korea. Panel least-squares vector autoregressions were used to estimate the short-term effect of Coronavirus transmission rates on stock market index returns. The results indicated that at a $99 \%$ confidence level, daily stock market returns are reduced by $2.3 \%$ for every $1 \%$ increase in viral infection rates across countries. Meanwhile, COVID-19 has been shown to harm global commodity prices such as platinum, silver, Brent crude, and West Texas Intermediate oil [3]. Research by Chien et al. also confirms that stock market, oil demand, gross domestic product, and electricity demand indices declined significantly as the severity of the pandemic increased. The time-frequency relationship between the New COVID-19 pandemic and instability in oil prices and stock markets, geopolitical risk, and economic policy uncertainty in the United States, Europe, and China was also examined. Oil prices, USEPU, the U.S. Geopolitical Risk Index, and the U.S. Equity Price Index, which are the daily COVID-19 observations, were analyzed by using a coherent wavelet approach and a wavelet-based Granger causality test [4].

The influence of COVID-19 on stocks in China and the United States has also attracted several scholars to research. Yousfi et al. evaluated the impacts of the Coronavirus on the risk spillover of the United States and Chinese stock markets. Considering the Cboe Volatility Index and Economic Policy Uncertainty Index, the association between daily confirmed cases and the U.S. stock market (from 13 January 2020 to 21 September 2020) was investigated. Wavelet coherence and DCC processes, multivariable GARCH models, specifically DCC-GARCH and ADCC-GARCH, were used. The findings revealed that volatility spillovers between U.S. and Chinese markets were stronger during the pandemic than before the outbreak. The continuing rise in the number of daily cases and deaths has increased uncertainty in the U.S. stock market and has affected U.S. financial markets and macroeconomic conditions [5]. Sansa and Hasan researched the effect of the COVID-19 on the Financial Markets from the period dated 1 March 2020 to 25 March 2020 in China and the United States. A Simple Regression in Double Log and Semi Log-Linear Models was applied. Sansa and Hasan used the Shanghai Stock Exchange as a sample for China and the New York Dow Jones as a sample for the United States. The investigations indicated that there is a significant positive relationship between confirmed cases of COVID-19 and all the financial markets in China and the United States, showing that the COVID-19 had a significant impact on the financial markets [6].

As a devastated country under the pandemic, the U.S economy is valuable to be analyzed. The volatility in global financial markets and the U.S. financial markets are also worth discussing. Thorbecke has found a correlation between returns and macroeconomic factors. The data used is the stock returns for 125 sectors from 19 February 2020 to 10 July 2020 . The main equation is the regression of eight macroeconomic variables and stock portfolio returns. The result highlighted that recovery from the health crisis is as important as macroeconomic rehabilitation. However, some sectors are more likely to 
depend on the release from the outbreak of COVID-19, such as the hospitality industry, and the other sectors have been harmed by the loss of production lines and equipment [7]. Ali et al. explored the financial markets' reactions under COVID-19 and revealed how sensitive and volatile the global market is during the pandemic. As the stock market is an adequate indicator of investors' expectations, the dataset used in this research is the MSCI indices for nine countries. In addition, the model used to diagnose the volatility of financial markets is the Exponential GARCH model. The findings demonstrate that COVID-19 is a severe threat to the global markets, and there is a causal relationship between the spread of COVID-19 and the deterioration of the markets. The financial markets around the world have faced a high degree of uncertainty and volatility [8]. Albulescu's research is more specific, focusing on examining the influence of Coronavirus pandemic uncertainty on U.S. financial market volatility. Daily data for worldwide and the United States reports from 11 March 2020 were analyzed. The Standard and Poor's 500 indexes' realized volatility was utilized as a proxy for volatility in U.S. financial markets. The results show that both global and the United States confirmed cases and deaths had increased volatility in the U.S. financial markets, particularly concerning mortality. Besides, the impact of global cases reported is greater than the impact of data reported in American. In addition, the economic policy uncertainty index did not significantly influence financial volatility during the COVID-19 pandemic [9].

The economic influence on the policies and measures taken by different countries and companies in response to the Coronavirus outbreak is also crucial. D'Orazio and Dirks studied the fiscal stimulus packages during the spread of the COVID-19 between March and May 2020 in the Euro Area. A panel data regression approach was used to identify the time-varying relationship between the dependent and independent variables by controlling for the characteristics of different countries. This paper considered the announcements of fiscal and COVID-19 related policies, measured these policies' effects on the stock market behavior, and provided evidence for a significant negative effect of changes in bond yields, EU market volatility, and Google trends on financial markets dynamics. By considering COVID-19 related policies, the study showed that besides having economic effects on GDP growth and inflation, expectations of economic agents also quickly spread to financial markets [10]. Karlin and Sierra-Escalante presented the rise of blended concessionary finance in COVID-19 by investigating and comparing IFC and other DFI responses after the private sector in emerging markets. The result suggested that as an effective way to stimulate innovative private sector projects and initiatives in emerging markets, blended concessional finance is an adequate solution to the problem of significant market and financial uncertainty by placing important projects within the risk appetite of the private sector investors and DFIs [11].

\subsection{Objective}

Since the COVID-19 had ravaged the world in March 2020, the economies of many countries have been affected. The purpose of this paper is to investigate the impact of the pandemic on the United States financerelated industries, including four main sectors, Banking, Trading, Insurance, and Real Estate. A comparative analysis was also conducted to determine the changes in each factor of the Fama-French five-factor model before and during the COVID-19. The suitability of the FamaFrench five-factor model for this study will also be discussed.

\section{METHOD}

The CAPM model mainly represents the relationship between the system risk rate of return. Namely, the rate of return of a single investment portfolio equals the sum of the risk-free rate of return and the risk premium.

The equation of the CAMP model is

$$
E\left(r_{i}\right)=r_{f}+\beta_{i}\left(E\left(r_{i}\right)-r_{f}\right)
$$

Where $E\left(r_{i}\right)$ represents the expected return of investment and $r_{f}$ means risk-free rate. $\beta_{i}$, the beta of the investment, is the system risk coefficient of a certain combination. $E\left(r_{i}\right)-r_{f}$ equals to the market risk premium.

A study by Fama and French in 1992 on the factors that determine the difference in the returns of different stocks in the U.S. stock market found that the beta value of the stock market cannot explain the difference in the return of different stocks, while the market value, bookto-market ratio, and price-to-earnings ratio of listed companies can explain the difference in stocks and the difference in the rate of return. Fama and French believe that the excess mentioned above returns compensate for risk factors not reflected by $\beta$ in CAPM.

Fama and French pointed out in 1993 that a threefactor model can be established to explain stock returns. This model believes that the excess return of an investment portfolio (including a single stock) can be explained by its exposure to three factors, which are market asset portfolio ( $\mathrm{Rm}-\mathrm{Rf})$, market value factor (SMB), book-to-market value ratio Factor (HML) [12]. This multi-factor equilibrium pricing model can be expressed as:

$$
E\left(R_{i t}\right)-R_{f t}=\beta_{i}\left(E\left(R_{m t}\right)-R_{f t}\right)+s_{i}^{E}\left(S M B_{t}\right)+
$$

In the past 20 years, many scholars have conducted empirical analysis on the three-factor model and found that some stocks are significantly non-zero. This finding 
shows that the three risks (factors) in the three-factor model cannot explain all the excess returns. Afterward, Fama and French discovered that in addition to the above risks, there are also profit level risks and investment level risks that can also bring excess returns to individual stocks; then, in 2013, they proposed a five-factor model. This model explains more about the excess returns of individual stocks, and its expression is: $R_{i}=a_{i}+b_{i}+R_{M}+s_{i}+E(S M B)+h_{i}+E(H M I)+$ $r_{i}+E(R M W)+c_{i}+E(C M A)+e_{i}$

As shown in Equation (3), the Fama-French fivefactor model has two more factors than the three-factor model: $\mathrm{E}(\mathrm{RMW})$ is the return difference between high and low-profit stock portfolios, and E(CMA) is the low/high reinvestment ratio company The difference in the return of the stock portfolio. These two factors describe the profit level risk and the investment level risk, respectively (note that the investment level here is not the investment level of the secondary market but can be easily explained as the enterprise's ability to expand reproduction). Similar to the three-factor model, the fivefactor model uses the same method, multiple linear regression, for parameter estimation. Here is the unexplained excess return in the five-factor model [13].

\section{RESULTS}

In this study, the data were adopted from Kenneth R. French's data library [14]. Two aspects of data have been picked: the daily portfolios average value-weighted return and daily values of Fama-French five factors, both from The Center for Research in Security Prices (CRSP) database. To investigate the performance of the U.S. market under COVID-19, there are two time periods focused on: before (May 2019 to February 2020 ) and After (March 2020 to December 2020) the pandemic. Additionally, the Coronavirus outbreak has cut all of the face-to-face meetings and caused widespread concerns. At the same time, the finance-related industry heavily relies on connections with customers and businesses worldwide. Therefore, due to the sensitivity and volatility of financial services during the COVID-19 crisis, the finance-related industry (including Banking, Trading, Insurance, and Real Estate) has been selected as the object of the study. The tool used to analyze the data is regression.

\section{1. p-value analysis}

Table 1 and Table 2 display the summary statistics for the Fama-French five factors before and after the COVID-19 outbreak. The null hypothesis made is that the sizes of five factors are different from zero. By analyzing the $\mathrm{p}$-value, if the $\mathrm{p}$-value is under 0.05 (significant level) and positive, then the factor impacts portfolios' returns, namely rejecting the null hypothesis.

For the Banking sector, Fama-French five factors had p-values below the significant level of 5\%, denoting that they all influenced the portfolios' returns before and after the pandemic. In parallel, for the Trading sector, four factors, except CMA, had effects on the returns. In other words, the Fama-French five factors of these two sectors have not been affected remarkably by the COVID-19.

However, in terms of Insurance, RMW had a change during the outbreak. In the pre-COVID period, the $\mathrm{p}$ value of RMW is 0.045 . This data means that profitability affected the returns of portfolios, specifically investing in the portfolios with robust profitability was worthier than with weak profitability. While after the pandemic erupts, the p-value became 0.081 (above 0.05 ), which indicates that this factor is not different from zero. There is no difference in investing with various profitability levels.

Similarly, for Real Estate, the COVID-19 affected HML and CMA significantly. Before the outbreak, the difference of $\mathrm{B} / \mathrm{M}$ ratios of portfolios and various investment styles did not influence the portfolios' returns: p-values of HML and CMA are 0.171 and 0.590, respectively. Nevertheless, after the outbreak, the pvalues of these two factors drop below 0.05 , reflecting that HML and CMA had played essential roles on returns of portfolios after the emergence of COVID-19.

Table 1. Statistics for Fama-French Five factors of 4 sectors in finance-related industry before the COVID-19, May 2019 to February 2020

\begin{tabular}{c|cccccc}
\hline Industry & Factor & Coefficient & t Stat & P-value & Lower 95.0\% & Upper 95.0\% \\
\hline \multirow{5}{*}{ Banking } & MKT-RF & 1.168 & 46.793 & 0.000 & 1.118 & 1.217 \\
& SMB & -0.129 & -2.764 & 0.006 & -0.221 & -0.037 \\
& HML & 0.717 & 14.960 & 0.000 & 0.622 & 0.811 \\
& RMW & -0.379 & -4.820 & 0.000 & -0.534 & -0.224 \\
& CMA & -0.212 & -2.286 & 0.023 & -0.394 & -0.029 \\
\hline \multirow{6}{*}{ Trading } & MKT-RF & 1.122 & 34.123 & 0.000 & 1.057 & 1.187 \\
& SMB & -0.178 & -2.891 & 0.004 & -0.299 & -0.057 \\
& HML & 0.437 & 6.927 & 0.000 & 0.313 & 0.562 \\
& RMW & -0.480 & -4.629 & 0.000 & -0.684 & -0.275
\end{tabular}




\begin{tabular}{c|cccccc} 
& CMA & -0.031 & -0.252 & 0.801 & -0.271 & 0.210 \\
\hline \multirow{5}{*}{ Insurance } & MKT-RF & 0.974 & 21.893 & 0.000 & 0.887 & 1.062 \\
& SMB & -0.096 & -1.154 & 0.250 & -0.260 & 0.068 \\
& HML & 0.196 & 2.294 & 0.023 & 0.028 & 0.365 \\
& RMW & -0.283 & -2.019 & 0.045 & -0.560 & -0.007 \\
& CMA & 0.285 & 1.728 & 0.086 & -0.040 & 0.611 \\
\hline \multirow{5}{*}{ Real } & MKT-RF & 1.033 & 18.753 & 0.000 & 0.925 & 1.142 \\
& SMB & 0.531 & 5.142 & 0.000 & 0.327 & 0.734 \\
& HML & 0.145 & 1.374 & 0.171 & -0.063 & 0.354 \\
& RMW & 0.171 & 0.987 & 0.325 & -0.171 & 0.514 \\
\hline
\end{tabular}

Table 2. Statistics for Fama-French Five factors of 4 sectors in finance-related industry after the COVID-19, March 2020 to December 2020

\begin{tabular}{|c|c|c|c|c|c|c|}
\hline Industry & Factor & Coefficient & $t$ Stat & P-value & Lower $95.0 \%$ & Upper $95.0 \%$ \\
\hline \multirow{5}{*}{ Banking } & MKT-RF & 1.085 & 48.002 & 0.000 & 1.040 & 1.129 \\
\hline & SMB & -0.134 & -2.316 & 0.022 & -0.249 & -0.020 \\
\hline & HML & 1.044 & 22.110 & 0.000 & 0.951 & 1.138 \\
\hline & RMW & -0.240 & -2.480 & 0.014 & -0.431 & -0.049 \\
\hline & CMA & -0.411 & -3.329 & 0.001 & -0.654 & -0.167 \\
\hline \multirow{5}{*}{ Trading } & MKT-RF & 1.095 & 52.629 & 0.000 & 1.054 & 1.137 \\
\hline & SMB & -0.154 & -2.889 & 0.004 & -0.260 & -0.049 \\
\hline & HML & 0.516 & 11.860 & 0.000 & 0.430 & 0.602 \\
\hline & RMW & -0.505 & -5.664 & 0.000 & -0.680 & -0.329 \\
\hline & CMA & 0.025 & 0.217 & 0.829 & -0.199 & 0.249 \\
\hline \multirow{5}{*}{ Insurance } & MKT-RF & 1.051 & 34.974 & 0.000 & 0.992 & 1.110 \\
\hline & SMB & -0.099 & -1.287 & 0.200 & -0.251 & 0.053 \\
\hline & HML & 0.353 & 5.623 & 0.000 & 0.229 & 0.477 \\
\hline & RMW & -0.225 & -1.749 & 0.082 & -0.478 & 0.029 \\
\hline & CMA & 0.027 & 0.166 & 0.869 & -0.296 & 0.351 \\
\hline \multirow{5}{*}{$\begin{array}{l}\text { Real } \\
\text { Estate }\end{array}$} & MKT-RF & 1.132 & 22.475 & 0.000 & 1.033 & 1.232 \\
\hline & SMB & 0.472 & 3.650 & 0.000 & 0.217 & 0.727 \\
\hline & HML & 0.659 & 6.257 & 0.000 & 0.451 & 0.867 \\
\hline & RMW & 0.080 & 0.369 & 0.713 & -0.346 & 0.505 \\
\hline & CMA & -0.652 & -2.370 & 0.019 & -1.194 & -0.110 \\
\hline
\end{tabular}

\section{2. $R^{2}$ analysis}

Table 3 shows how $\mathrm{R}^{2}$ of the Fama-French fivefactor model changed before and after the COVID-19 outbreak. In general, the $\mathrm{R}^{2}$ of all four sectors in the finance-related industry are high during the observable periods, which demonstrates that Fama-French five factors are highly statistically significant.

To be more specific, for Insurance, $\mathrm{R}^{2}$ rises from $72.8 \%$ to $89.0 \%$, indicating that removing one factor, RMW, has resulted in lifting the $\mathrm{R}^{2}$ higher. Similarly, for
RIEst, $\mathrm{R}^{2}$ increases from $72.3 \%$ to $83.1 \%$, meaning that adding two factors HML and CMA, has a significant impact on $\mathrm{R}^{2}$ and makes the portfolio return more correlated to the benchmark.

Table 3. $\mathrm{R}^{2}$ of 4 sectors in finance-related industry, before and after the COVID-19 outbreak

\begin{tabular}{ccc}
\hline R Square & Before & After \\
\hline Banking & 0.934 & 0.960 \\
Trading & 0.871 & 0.951
\end{tabular}




\begin{tabular}{ccc} 
Insurance & 0.728 & 0.890 \\
Real Estate & 0.723 & 0.831 \\
\hline
\end{tabular}

\section{DISCUSSION}

This paper applied Fama-French five-factor model to analyze the finance-related industries' changes in the U.S. market before and after the COVID-19. By comparing the different performances of each sector before and after the pandemic, the various coefficients and their validity are analyzed. Possible reasons for the differences are also discussed. The Fama-French five factors for the Banking and Trading sectors were not significantly affected by the pandemic. However, the RMW for the Insurance sector and the HML and CMA for the Real Estate market industry changed considerably during the COVID-19. Therefore they are the focus of discussion.

\subsection{Banking}

From Table 1 and Table 2, the results indicate that the Fama-French five factors in the Banking industry before and after the pandemic are different from zero, indicating that they all impacted the returns of the investment portfolios before and after the COVID-19. However, COVID-19 has not caused a statistically significant change in the Fama-French five-factor of Banking. The reason might be that Banking has become more focused on stress testing, risk monitoring and identification, and stricter capital and liquidity requirements in the wake of the 2008 financial crisis. This observation has led the Banking to anticipate the damage to the economy from the pandemic. Baret et al. pointed that aggressive market interventions by central Banks have further boosted liquidity in Banking. For example, the Fed cut the federal funds rate by 50 basis points and intervened aggressively in the repo market [15].

However, compared to the other factors, the change in HML is relatively large, with the coefficient increasing from around 14.960 to 22.110. This increasing relationship implies that banks with a high book-tomarket ratio perform better than those with a relatively low book-to-market ratio during the pandemic. This result may have been caused by concerns about the ongoing economic damage caused by the COVID-19, leading to a desire to transfer assets to Banks with high book values and greater liquidity.

\subsection{Trading}

In the Trading sector, except for CMA, the other four factors are significantly different from zero before and after COVID-19, meaning that these factors play important roles on the portfolios' returns of the industry. Similar to Banking, Trading has not been affected significantly by the pandemic. However, financial markets fell sharply after the outbreak, and stock market crashes were seen as lucrative opportunities by retail investors after the initial panic. Most countries saw a marked increase in retail participation in Trading markets [16]. The influx of retail investors has increased the volume of transactions, which improved the liquidity. It may be one of the possible reasons for explaining why COVID-19 did not significantly influence the Trading sector. In the opinion of Talwar et al., the financial attitudes of investors during the pandemic period were measured from multiple dimensions, and the results reveal that they all had a positive impact on Trading activities [17].

\subsection{Insurance}

For Insurance, RMW is the only factor that has changed significantly during the COVID-19. RMW is a for-profit factor. The asset's profitability determines the discount rate of its future cash flow and affects the pricing of capital. The particular reason for the circumstance is that profitability affects the returns on the portfolio. During the COVID-19 period, investors tended to invest in strongly profitable portfolios and abandon weak ones. After the COVID-19, there is no difference in investments at different profit levels. Under the COVID-19 control measures, the insurance business is difficult to develop, and the demand for human life insurance has dropped sharply. Due to the economic downturn, the everyday business of transportation, manufacturing, tourism, and other industries is blocked, increasing commercial health insurance, property insurance, and other compensation. This fact brings operating pressure to insurance companies.

The incremental auto insurance business will decline significantly affected by the sharp decrease in new car sales during the pandemic. At the same time, the pandemic has increased the market risk of the use of insurance funds, resulting in increased volatility in the stock market and causing pressure on the income of insurance funds' utilization. It also increases the risk of credit default when operating the insurance funds. These problems reduce the profitability of the Insurance industry. For example, New York Life Insurance Company earned $\$ 44,116.6$ (Revenue) million and $\$ 1,003.8$ million (net income) in 2020, while margins fell nearly $4 \%$. Many small and medium-sized insurance companies are affected by the insurance market demand, insurance products prices, insurance fees level, and return on investment. The company's profitability declined and fell into a business crisis. Therefore, the change of the RMW factor reflected the performance of Insurance under COVID-19; using this factor enables a better analysis of corporate profitability. 


\subsection{Real Estate}

Discussing the Fama-French five-factor model, one of the essential factors is HML, indicating that valuebased companies outperform growth-oriented companies. This rule also applies to the Real Estate sector. The data shows that the impact of the COVID-19 on the Real Estate sector is significant. The control measures taken in response to the pandemic have directly decreased the sales of Real Estate and the development of new projects. Similarly, COVID-19 has had a non-negligible influence on the economy, first of all on the Real Estate industry. Enterprises have borne massive financial pressure, and COVID-19 has slowed down the flow of funds back to enterprises and caused a burden on the enterprises.

On the other hand, COVID-19 has also caused a decline in residents' income, and the demand for Real Estate has also turned into maintaining income. HML factor illustrates that value stocks (high book-to-market value ratio) enjoy higher returns than growth stocks (low book-to-market value ratio) [18]. Comparing the data before COVID-19, the HML coefficient of the Real Estate industry was 0.145. After COVID-19, the HML coefficient became 0.659 . This observation demonstrates that before the pandemic, both value-oriented Real Estate companies and growth-oriented Real Estate companies had reasonable rates of return. However, the impact of COVID-19 on growth companies is significantly greater, so after the pandemic, mature value companies can recover from the effects of the pandemic quickly by relying on a solid economic foundation.

Another factor that changed during the crisis is CMA. In the Real Estate market, before the COVID-19, the investment attitudes did not influence the returns of portfolios. However, after the outbreak, investors tend to prefer the conservative portfolios, meaning that investing in low return is worthier than investing in high return.

One explanation is that Coronavirus led to a sudden pandemic worldwide; the Real Estate industry does not prepare for emergencies in advance. Many countries, including the United States, have taken lockdown measures to inhibit the spread of disease. The consequences caused are the increase in the unemployment level and the stagnation of construction works: fewer people have the budget to purchase new houses and repay the debts, and companies spend more cost on suspending the time limit of Real Estate projects. As a result, Real Estate activity declines after the COVID-19, both demand and supply decreasing. Investors have realized the unusual variations and severe impacts on the Real Estate markets. The uncertainty of returns of the Real Estate portfolios increases, which means that risky portfolios will become risker but with uneven returns. However, those who hold the conservative portfolios, such as long-term mortgages, have not been significantly affected by aggressive investors. Thus, investors tend to move towards portfolios with low returns and low-risk rates to cover their losses and be more conscious about this abrupt event.

As Himanshu et al. investigated, due to the COVID19, investors have considered reallocating their proportions about portfolios between conservative and aggressive [19]. The outbreak has shaken up the status quo and changed the behavior of investors. The Real Estate market is sensitive; the outbreak has cut the ways of visiting houses for sale and eliminated the opportunities of substituting house properties. The purpose of investment is to gain higher returns and to bear less risk. Nevertheless, risky portfolios' expected returns are not optimistic; investing in conservative assets is a preferable avenue.

\section{CONCLUSION}

This article selects four finance-related industries (Banking, Trading, Insurance, Real Estate) in the United States and employs the Fama-French five-factor model to analyze the data changes during the COVID-19. The regression method is used to investigate the performance of sectors in depth. After the outbreak, investors in these industries have responded to the crisis and changed their investment styles and strategies. By inspecting the behavior of Fama-French five factors, RMW, HML, and CMA of Insurance and Real Estate industries were statistically significant, demonstrating that Fama-French five-factor model is a valid model to investigate the performance of industries. Moreover, this paper is meaningful for understanding the impact of the pandemic on the U.S. finance-related industries and helpful for investors to predict the trend of these industries in the event of a future outbreak and make the right investment decisions. At the same time, more comprehensive research will likely be available to help investors better analyze the socio-economic impact of viral disasters in the future.

\section{REFERENCES}

[1] Horváth, D., \& Wang, Y. (2021). The examination of Fama-French Model during the Covid-19. Finance Research Letters, 41, 101848.

[2] Chikri, H., Moghar, A., Kassou, M., Hamza, F., \& Bourekkadi, S. (2020). The asymmetric influence of covid-19 on financial market: evidence from nardl model. Communications of the IBIMA, 1565715673.

[3] Hassan, S. \& Gavilanes, J.M.R. (2021). First to React Is the Last to Forgive: Evidence from the Stock Market Impact of COVID 19. Journal of Risk 
and Financial Management, 14(1), 26. https://doi.org/10.3390/jrfm14010026

[4] Chien, F., Sadiq, M., Kamran, H. W., Nawaz, M. A., Hussain, M. S., \& Raza, M. (2021). Co-movement of energy prices and stock market return: environmental wavelet nexus of COVID-19 pandemic from the USA, Europe, and China. Environmental Science and Pollution Research, 28(25), $32359 . \quad \mathrm{https} / / \mathrm{doi}-$ org.liverpool.idm.oclc.org/10.1007/s11356-02112938-2

[5] Yousfi, M., Zaied, Y.B., Cheikh, N.B., Lahouel, B.B., \& Bouzgarrou, H. (2021). Effects of the COVID-19 pandemic on the US stock market and uncertainty: A comparative assessment between the first and second waves. Technological Forecasting \& Social Change, 167, 120710. https://doi.org/10.1016/j.techfore.2021.120710

[6] Sansa, N.A. (2020). The impact of the covid-19 on the financial markets: evidence from china and usa. SSRN Electronic Journal.

[7] Thorbecke, W. (2020). The Impact of the COVID19 Pandemic on the U.S. Economy: Evidence from the Stock Market. Journal of Risk and Financial Management, 13(233), 233.

[8] Ali, M., Alam, N., \& Rizvi, S. (2020). Coronavirus (COVID-19) - An epidemic or pandemic for financial markets. Journal of Behavioral and Experimental Finance, 27, 100341.

[9] Albulescu, C. T. (2021). COVID-19 and the United States financial markets' volatility. Finance Research Letters, 38, 101699-101699. https://doi.org/10.1016/j.frl.2020.101699

[10] D'Orazio, P. \& Dirks, M. W. (2020). Covid-19 and financial markets: assessing the impact of the coronavirus on the eurozone. Ruhr Economic Papers.

[11] Karlin, A., \& Sierra-Escalante, K. (2021). Blended Concessional Finance and COVID-19. The World Bank Group.

[12] French, K. (2021). Kenneth R. French - Description of Fama/French Factors. Retrieved 13 August 2021, from https://mba.tuck.dartmouth.edu/pages/faculty/ken.f rench/Data_Library/f-f_5_factors_2x3.html

[13] Hayes, A. (2021). Fama and French Three Factor Model Definition. Retrieved 13 August 2021, from https://www.investopedia.com/terms/f/famaandfre nchthreefactormodel.asp
[14] French, K. (2021). Kenneth R. French - Data Library. Retrieved 13 August 2021, from https://mba.tuck.dartmouth.edu/pages/faculty/ken.f rench/data_library.html

[15] Baret, S., Celner, A., O'Reilly, M., \& Shilling, M. (2020). COVID-19 potential implications for the banking and capital markets sector. Maintaining Business And Operational Resilience, 11(8), 74-88

[16] Dubey, S. (2021). Mobile Trading Spikes As Retail Investors Flock To Equity Markets. Retrieved 17 August 2021, from https://www.bloombergquint.com/markets/mobiletrading-spikes-as-retail-investors-flock-to-equitymarkets

[17] Talwar, M., Talwar, S., Kaur, P., Tripathy, N., \& Dhir, A. (2021). Has financial attitude impacted the trading activity of retail investors during the COVID-19 pandemic?. Journal of Retailing and Consumer Services, 58, 102341.

[18] Fernando, J. (2021). Understanding High Minus Low (HML). Retrieved 19 August 2021, from https://www.investopedia.com/terms/h/high_minus _low.asp

[19] Himanshu, H., Ritika, R., Mushir, N., \& Suryavanshi, R. (2021). Impact of COVID-19 on portfolio allocation decisions of individual investors. Journal of Public Affairs, E2649. 